UDC: $821.134(7 / 8)^{\prime} 255.54=135.1$

DOI: https://doi.org/10.18485/hispserb.2019.2.ch22

\author{
Ilinca Ilian ${ }^{1}$ \\ Universidad del Oeste de Timisoara \\ Rumanía
}

\title{
LA LITERATURA LATINOAMERICANA: QUÉ Y CÓMO SE TRADUCE EN LA RUMANÍA DE HOY
}

\begin{abstract}
Resumen
Este artículo se propone hacer una descripción comentada de la traducción al rumano de la literatura latinoamericana, a fin de ofrecer un material que ulteriormente podría ponerse en relación con la presencia de la misma literatura en los espacios culturales de otros países de Europa Central y del Sureste. Fruto de una ya larga investigación del fenómeno traductivo del español al rumano, el artículo pone de relieve ciertos trazos característicos del panorama editorial rumano en relación con la cultura latinoamericana: el gran número de autores relacionados con el fenómeno del Boom, por un lado, y la dificultad de introducir en Rumania a los nuevos autores latinoamericanos en el contexto de una disminución de la práctica lectora reflejada en las estadísticas realizadas en Rumania, por otro lado. A lo largo del artículo se plantean una serie de preguntas sobre la práctica lectora en el contexto posmoderno avanzado.

Palabras clave: recepción de la literatura latinoamericana, Rumanía, Europa Central y del Sureste, política editorial, lectura.
\end{abstract}

$\overline{{ }_{1}^{1} \text { ilincasn@gmail.com }}$ 
Debido a los transcendentales cambios políticos ocurridos a finales de 1989, el paisaje cultural rumano se transformó de forma radical en los años noventa y, espoleada por la sed de libertad durante tantas décadas sofocada, hubo una verdadera explosión del número de editoriales y revistas de las más distintas orientaciones. Los años noventa representan, desde el punto de vista cuantitativo, el período más dinámico de la cultura escrita en Rumania, si se piensa que en 1990 existían 1444 periódicos, entre ellos 65 diarios, cuyo número creció hasta 1992 a $102(\operatorname{Rad} 2008$ : 190). Por su parte, el número de las editoriales se multiplicó por miles: si en el período socialista funcionaba 23 editoriales, entre las cuales 17 regidas por el sistema de la Central editorial y 5 subordinadas a otros organismos específicos (Simionescu \& Buluță 1981: 132-133), en 2016 funcionaban de forma activa (o sea, publicando al menos 10 títulos al año) 1956 editoriales de las 6157 editoriales fundadas desde 1990 (Ceobanu et al. 2016: 20). Evidentemente, de estas miles de editoriales, solo un número muy reducido, alrededor de unas 25 , representan unos actores realmente importantes en el mercado del libro rumano, en el sentido de que tienen una buena red de distribución y unas tiradas significativas.

En otros artículos (Ilian 2016, 2018a, 2018b) intentamos hacer un balance de la recepción de la literatura latinoamericana en Rumania en el período anterior y posterior a 1989 y mostramos que, igual que en otros espacios de Europa, en Rumania también existió un relativo solapamiento entre la efectiva producción literaria latinoamericanos y los estereotipos ligados al exotismo de esta literatura que la afectaron desde los primeros años de su penetración en las culturas extranjeras. En este orden de ideas, Gustavo Guerrero, en un interesante artículo, sugiere que la inicial incomprensión de Rubén Darío en Europa es el sello de la relación de la literatura latinoamericana con las culturas extranjeras: la fría acogida del poeta nicaragüense en Francia se debió principalmente a la imposibilidad de conciliar su propuesta artística, original y revolucionaria, con las expectativas de sus lectores franceses, que esperaban de él, como de los otros modernistas latinoamericanas, un discurso literario ligado al exotismo. Se trataba pues de un exotismo precisamente de origen galo, en un gesto similar al descrito por Edward Said con respecto al orientalismo creado por los poderes centrales europeos. Decía Valéry Larbaud "no les pedimos [a los poetas latinoamericanos] poemas del Barrio Latino [... sino] visiones de villas tropicales, blancas y voluptuosas ciudades de las Antillas, [...] el espectáculo de la naturaleza, la nota exótica, la tristeza, la melancolía y asimismo el tedio que se desprende de ciertos paisajes andinos" (apud Guerrero 2007: 24). No yerra, pues, Gustavo Guerrero, 
cuando afirma que, al estallar el Boom, la recepción de la literatura latinoamericana "lejos de realizarse sobre la base de un horizonte inédito, plural y abierto, se produce dentro de una configuración simbólica que incorpora, modulándolo, el viejo horizonte exótico" (26). El "realismo mágico", convertido en una marca identificadora para la literatura de este continente, tanto en el espacio de origen como en el extranjero, aboga a favor de esta opinión y no creemos que se pueda negar que, si bien los cuatro autores centrales del Boom gozaron de una excelente acogida en las culturas extranjeras, es García Márquez quien representó para todos los países europeos la encarnación de la máxima originalidad de esta literatura y de su especificidad más incontrovertible.

En lo que toca a la cultura rumana, los autores vinculados al Boom, independientemente de su generación, se integran paulatinamente gracias a dos factores interconectados: por un lado, gracias al impacto mundial de este fenómeno literario, cuajado precisamente en torno a la Revolución Cubana, por otra parte, debido a la afinidad ideológica de muchos de sus representantes, en su mayoría de orientación de izquierdas. En la Rumania socialista, así como nos propusimos mostrar en las otras ocasiones mencionadas, los grandes autores vinculados al Boom, desde Asturias, Carpentier, Borges hasta Puig y Bryce Echenique, igual que, evidentemente, los escritores centrales del este fenómeno (Cortázar, Fuentes, García Márquez y Vargas Llosa) tuvieron una acogida entusiasta en la literatura rumana, fertilizando la expresión de esta y dejando su impronta en la generación de los autores que se formaban o ya se manifestaban en aquel momento. Más allá del aspecto político, que tuvo cierto peso, pero no fundamental, en la importación de esta literatura, los autores latinoamericanos tuvieron en Rumania una recepción sincrónica y similar con la existente en toda Europa, dado que, a pesar del totalitarismo y de todas las diferencias que este acarreaba con respecto a los países libres, Rumania tenía un horizonte de expectativas similar al de la Europa occidental para la acogida de este fenómeno mundial (Ilian 2018b: 61). Más precisamente, la recepción de esta literatura se realizó de una forma que combinaba, en proporciones iguales, el placer del reconocer las formas familiares de la tradición occidental y el desvío "exotizante" de una escritura que abordaba un universo insólito, perturbador, lo que explica en gran medida la excelente recepción de las letras latinoamericanas entre 1960 y 1989 en todo el mundo, incluida Rumania.

Un factor que se debe tomar en cuenta en todo estudio relacionado con la recepción literaria es el cambio fundamental provocado por la masificación de la producción de libros, que empieza en los años 
ochenta, se acelera con la aparición de Internet y la creación de los libros electrónicos y audiolibros y que actualmente se confronta con una "quinta ola" de transformación, llamada la "economía de la atención", esto es la competencia por la atención del público cada vez más interesado por el tipo de cultura promovida a través de Youtube y Netflix (Wischebart 2019: 11). En estas condiciones, todo balance de los libros publicados en cierto espacio cultural debe tomar en cuenta los fenómenos relacionados con la presión económica ejercitada por los grandes trusts editoriales, la promoción sesgada de ciertos autores y ciertos subgéneros ficcionales, así como la propia demanda de lectura entre los consumidores.

En el caso de la recepción de la literatura latinoamericana después de 1990, sobre el fondo de las modificaciones sufridas por la cultura escrita que acabamos de mencionar, se deben tomar en cuenta dos aspectos suplementarios, eso sí, bastante dispares: uno está ligado a la impresión de cohesión de la manifestación literaria latinoamericana de los años sesenta-setenta, cuando, a pesar de las enormes diferencias de poéticas de los integrantes del fenómeno del Boom, un crítico como Emir Rodríguez Monegal o un escritor como Carlos Fuentes podían sacar de relieve las líneas-fuerza comunes de unos escritores que, con instrumentos literarios dispares, se encaminaban a desentrañar la "identidad" latinoamericana concebida como más o menos homogénea desde el Cono Sur hasta México. Por otra parte, se da el aspecto relacionado con el grado de curiosidad lectora del público rumano, que, en el período socialista, por causa de la ausencia de otros pasatiempos y de una oferta cultural más o menos limitada, se dedicaba a una lectura mucho más asidua que en la actualidad. Esto creaba las condiciones para un consumo más igualitario de los bienes culturales brindados por las políticas culturales, en las cuales el dirigismo estatal tenía un peso marcado, aunque él se manifestaba de forma siempre sorprendente, con períodos de intensificación y de relajación, de intervención masiva o de relativa liberalización.

La relativa coherencia de cada uno de los dos aspectos mencionados anteriormente desapareció casi por completo después de 1990. Por un lado, es indudable que en el campo literario latinoamericano, a partir de los años noventa, se dio un fenómeno de disgregación radical, acompañada por un rechazo constante de la fórmula del "realismo mágico", convertida en su mera parodia por el exceso de su empleo en unos libros comerciales. Ya en 2003, en el Encuentro de los Autores Latinoamericanos de Sevilla, la mayoría de los - en aquel entonces - jóvenes autores participantes repudiaban la fórmula del "realismo mágico" y es sugerente la contra 
propuesta terminológica de Rodrigo Fresán, que, de cierta forma, ilustra la actitud general de su generación: "El irrealismo lógico es la contraparte complementaria del realismo mágico. Mientras el realismo mágico propone una realidad pública puntuada por reflejos fantásticos, mi irrealismo lógico apuesta por una irrealidad privada en la que, de tanto en tanto, es bombardeada por las esquirlas del orden" (Fresán 2004: 63). Como reacción a la obsesión identitaria de sus antecesores del Boom, se da asimismo una relativización hasta el abandono completo de las marcas identitarias tradicionales: no solo los escenarios de las novelas de los jóvenes autores se sitúan en espacios ajenos al continente de origen (Volpi ubica En busca de Klingsor en la Alemania nazi, Los impostores de Santiago Gamboa tiene como escenario la ciudad de Pekín, los libros del guatemalteco Rodrigo Rey Rosa se desenvuelven en lugares tan exóticos como Tánger, Grecia o la India etc.), sino que la propia adscripción a una tradición nacional se vuelve facultativa. Al respecto, en el mismo Encuentro de autores de Sevilla, Jorge Volpi apuntaba con humor que la nacionalidad no representa para su generación más que un dato anecdótico en las solapas del libro (Volpi 2004: 221). Estas posturas continuaban de hecho las orientaciones de los escritores reunidos en torno a McOndo y Krack que tuvieron en los años noventa una importante contribución a la socavación de una supuesta identidad supranacional coagulada en el campo literario en torno al "realismo mágico" y que asimismo prefirieron deshacerse de la etiqueta de "latinoamericanos" a fin de practicar una literatura de tipo nuevo. Todas estas tendencias disolutivas llevaron, en los años 2000, a una real puesta en duda de la pervivencia de una literatura latinoamericana, como lo ponen de relieve los títulos de unos artículos escritos por autores reconocidos de varios países latinoamericanos: "La literatura latinoamericana (ya) no existe" (Carlos Cortés 1999), "El fin de la narrativa latinoamericana" (Jorge Volpi 2004), "Y finalmente, ¿existe una literatura latinoamericana?" (Jorge Fornet 2007), "La desbandada. 0 por qué ya no existe la literatura latinoamericana" (Gustavo Guerrero 2009). Una tentativa de signo contrario se puede encontrar no obstante en un trabajo más reciente, de 2014, New Trends in Contemporary Latin American Narrative. Post-National Literature and the Canon, donde los autores Timothy Robbins y José Eduardo González decidieron emplear, al menos de forma provisional, el término de "escritores posnacionales" para la entera generación de los autores latinoamericanos que se afirman o maduran entre los años 1990 y 2010. Queda no obstante la pregunta si, para un lector del extranjero, que ha llegado a formarse una concepción precisa sobre la literatura latinoamericana, una "etiqueta" como la 
"posnacionalidad" atribuida a los autores latinoamericanos puede realmente funcionar a fin de desarraigar los estereotipos ya existentes, más cómodos, y de proporcionarle una visión adecuada acerca del fenómeno literario de este continente en su conjunto.

Pasando a las condiciones de la recepción de la literatura en el espacio rumano, en comparación con los años sesenta-ochenta del siglo pasado, es indudable que los hábitos de lectura en Rumania, de hecho como en todos los países del mundo, cambiaron por completo. Según los datos estadísticos reunidos a nivel europeo, Rumania se situó en los últimos lugares en lo que respecta el tiempo asignado a la lectura de libros y la adquisición de libros: sólo 2,8\% de los rumanos, conforme al sondeo publicado en 2017 por la Federación de Editores europeos, leen más de diez libros al año (en comparación con Serbia, 16,1 y Hungría, 14,1) (The Book Sector en Europe 2017: 19); si en 2007 38,7\% de la población rumana declaró haber leído un libro durante el último año, en 2011 la cifra se redujo a 29,6\% (en Serbia, en el mismo año, se registró una proporción de 52,8) (The Book Sector en Europe 2017: 18-19). Un sondeo rumano de IRES (Instituto Rumano para Evaluación y Estrategia) realizado en 2015 y publicado en la revista Sinteza mostró que 23\% de los participantes en la encuesta no compran ningún libro nuevo, 28\% compran menos de cinco libros al año y apenas un $17 \%$ compran entre cinco y diez libros al año, si bien $86 \%$ declaran que tienen una biblioteca en casa (Sinteza 2016: 12). El presupuesto invertido en la adquisición de los libros es bajo: $26 \%$ declara invertir anualmente en libros una cantidad entre 200 y 500 lei (alrededor de 43 y 108 euros) y solo 5\% gasta más de 1000 lei (unos 220 euros) (Sinteza 2016: 14). En cuanto a las preferencias de lectura, estas van por las novelas extranjeras: $31 \%$ declararon que el último libro leído fue una novela extranjeras, mientras que solo 15\% leyeron a un autor rumano (Sinteza 2016: 18)². Según las estadísticas hechas a nivel europeo, las tiradas medias en que se imprimen los libros en Rumania son entre las más bajas de Europa y la reducción del número de librerías es constante (The Book Sector en Europe 2017: 21). El valor total del mercado de libros en Rumania es de 60 millones de euros, mientras que en Hungría, con una población tres veces menor, el valor es triple. En Alemania este valor sube a siete mil millones de euros, en España de tres mil millones y en Italia de mil millones (Surcel 2017).

\footnotetext{
${ }^{2}$ Entre las preferencias declaradas se encuentran los autores rumanos clásicos y del período de entreguerras y como poeta favorito queda el poeta nacional Eminescu, lo que demuestra que los autores estudiados en el colegio quedan para muchos de los rumanos la referencia absoluto en materia de calidad literaria.
} 
Claro, todos estos datos se deben ver en su contexto preciso y hay que tomar en cuenta no solo las circunstancias políticas y macropolíticas y las políticas educativas y culturales, sino también la desigualdad cultural creciente en todo el mundo. Otro problema, que es también global, se refiere a la falta de coordinación de la oferta de libros con las políticas de fomento de la lectura reflexiva y sosegada, encaminada a cultivar en el sentido más profundo de esta palabra. Se asiste desde los años noventa a un enorme crecimiento del mercado de libros: para dar el ejemplo de España, que sin duda se puede generalizar, año tras año en este país se publican cada vez más libros ${ }^{3}$ y los títulos de literatura, que representan un pormedio de $21 \%$ de la producción anual (Panorámica 2016: 53), no dejan de acumularse a tal punto que el intento de seguir el fenómeno literario de la actualidad se vuelve una empresa cada vez más ardua, si no imposible. Ahora bien, la ocultación del valor no tanto por una censura directa sino por la inflación del lenguaje, ha sido detectada ya desde los años setenta, cuando el poeta y ensayista Bernard Noël, en su libro L'Outrage aux mots (1975) hablaba de la "sensura" (homónimo francés de "censura", con juego de palabras basado en "sens", sentido): el abuso de lenguaje "violenta la lengua, deformándola" (Noël 2011: 34) y provoca una censura por exceso, que lleva a la anulación del sentido. Así, el ruido mediático excesivo hace difícil si no imposible la detección de la real novedad y originalidad. El fenómeno del bestsellerismo es una consecuencia natural de mercantilización total de la cultura, pues, como observaba Francisco Caudet, estamos inmersos en "el colonialismo de la competencia canibalesca, del afán del dinero, de las carreras despiadadas tras la venta de ejemplares" (apud Becerra Mayor et al. 2013: 30). El caso más conocido es el cese de Ignacio Echevarría como crítico de la publicación Babelia por haber publicado en 2004 una reseña negativa a una novela de Bernardo Atxaga, impidiendo así la venta masiva de un

\footnotetext{
${ }^{3}$ Según el informe de la Panorámica de la edición española de libros, en 2017 el número de ISBN (libros impresos y en formato electrónico) alcanzaba la cifra de 89.962, con 4,6\% más que el año anterior (ABC cultural, 21/05/2018: https://www.abc.es/cultura/libros/ abci-espana-aumenta-produccion-libros-46-por-ciento-2017-201805211433_noticia. html). En 2016 de hecho la producción había subido también, con un 8,3\% con respecto a 2015, cuando la cifra de ISBN se estimó a 79.397 (Panorámica 2016: 6). De las cifras de los informes se desprende también un alza constante de las primeras ediciones (88.119 ISBN frente a 84.047 en 2016), en detrimento de las reediciones, que decrecen con 5,6\%. Los títulos de literatura representan un porcentaje bastante importante de esta producción, en 2013 situándose a 21,4\%, en 2015 subiendo a 21,9\% para volver en 2016 a 21,4\%. Entre estos títulos alrededor de 23\% lo representan las traducciones, la lengua dominante de la cual se traduce siendo el inglés (Panorámica 2016: 52). En el campo de los libros de literatura se dio en 2016 un alza de 11,2\% con respecto a 2015 (Panorámica 2016: 52-53).
} 
libro que se estimaba llegar a ser, por la fama del autor, un gran éxito en términos comerciales (Bértolo 2008: 269).

Es en este contexto en que se debe leer el balance de la literatura latinoamericana traducida en Rumania, porque es inútil mantener una división tajante entre la recepción literaria, proveedora de (alta) cultura, y la lógica del mercado orientado hacia el consumo masivo. Sin duda, los autores que se traducen al rumano no se publican, por más excelente que fuese su obra, solo por razones estéticas, sino también comerciales, y es innegable que lo mismo ocurre en todo el espacio de la Europa Central y del Sureste porque lo mismo pasa en todo el mundo.

A continuación nos proponemos hacer una descripción más atenta de las traducciones al rumano de la literatura latinoamericana, retomando en parte el parte, pero ampliándolo y comentándolo más profundamente, el cuadro que realizamos en otra parte (Ilian 2016; 2018a; 2018b). A lo mejor el hecho más llamativo de la recepción actual de la literatura latinoamericana en Rumania es la abundancia de los títulos relacionados con la literatura, o mejor dicho con cierta literatura del Boom. Por un lado, en la cultura rumana anterior a 1990 varios títulos del Boom faltaban, tanto por razones económico-políticas como por razones relacionadas con el natural desfase temporal de la traducción con respecto a la publicación de la obra en el espacio de origen. Así, es sumamente saludable el hecho de que varios títulos, algunos de ellos de los más importantes, que no se tradujeron en el momento de su publicación en castellano, se publicaron en Rumania después de 1990. Existe actualmente, en ediciones de varios precios y en reediciones múltiples, la traducción de la obra completa de Vargas Llosa y de García Márquez, mereciendo mencionarse que esta última ha sido prácticamente traducida de nuevo por una insigne traductora, Tudora Şandru-Mehedinți, que tradujo 13 de los 18 títulos del gran colombiano y, entre otros méritos, asumió la tarea de retraducir la obra maestra Cien años de soledad, publicada en 1975 en una traducción que dejaba mucho que desear. Es indudable que García Márquez es uno de los autores que más se publican y se venden en Rumania: no solo todas las obras del autor, tanto las de ficción como las de periodismo y las memorias, fueron publicados en la serie de autor creada por la editorial RAO, sino que también se tradujeron al rumano su biografía escrita por Dasso Saldívar (2016, dentro de la misma serie de autor de RAO) y el libro de conversaciones El olor a la guayaba (2008, Editorial Curtea Veche).

De forma poco sorprendente, un destino igual de fausto tiene Vargas Llosa, publicado en la serie de autor de la gran editorial rumana 
Humanitas, que tanto volvió a publicar, en reediciones sucesivas, los libros traducidos en el periodo 1970-1993, como tradujo, de manera inmediata, a medida que el Nobel peruano-español publicaba sus libros en España, sus nuevos títulos, independientemente de su género, novelas o ensayos.

En cuanto a Carlos Fuentes, es el autor que menos se tradujo en la Rumania socialista, donde solo apareció en 1969 La muerte de Artemio Cruz y Todos los gatos son pardos en la editorial Thalia en 1974, además de otras pocas obras de menores dimensiones en la prensa cultural. A partir de finales de los noventa se tradujeron otros varios títulos: en la editorial Univers, Gringo Viejo (1998), en la editorial Humanitas, Instinto de Inez (2002), Diana o la cazadora solitaria (2003), Constancia (2006), Inquietante compañía (2007), en la editorial Curtea Veche, La silla del águila (2004), En esto creo (2005), Todas las familias felices (2010), La voluntad y la fortuna (2011), en la editorial Art, se reeditó Todos los gatos son pardos (2007).

En cuanto a Julio Cortázar, su cuentística irrumpió en el espacio rumano desde los mediados de los años setenta y dejó un influjo importante en la cultura rumana, en cambio sus novelas debieron esperar varias décadas para ser traducidas: Los premios apareció en 1991 en la Editorial Cartea Romaneasca (simplemente porque el manuscrito, entregado varios años antes, no se publicó a tiempo), Rayuela apareció por un lado en la editorial Univers en 1998 y tuvo varias rediciones, y por otro lado en 2004 en la editorial Litera de Chisinau, de forma que hay actualmente dos traducciones de esta novela en la cultura rumana. El libro de Manuel se tradujo al rumano por la editorial Polirom en 2009 y 62. Modelo para armar, publicado por la editorial Art, en 2016, esta editorial creando a partir de 2015 la serie de autor Cortázar, donde volvió a publicar varias obras traducidas anteriormente y se propuso completar paulatinamente la lista de títulos esenciales del autor argentino, publicando por ejemplo La vuelta al día en ochenta mundos, en 2016, con un gran éxito de público. Por otra parte, a lo largo de las últimas dos décadas, varias antologías de los cuentos de Cortázar se publicaron por otra gran editorial rumana, Polirom, en algunos casos los editores prefiriendo volver a traducir ciertos cuentos ya existentes en las ediciones anteriores, no tanto por juzgar deficiente la primera traducción, sino por razones económicas. Tocamos aquí, desgraciadamente, un punto neurálgico de la industria editorial rumana, esto es el malo pago de las traducciones, los precios por página (se calculen como se calculen) empezando de un euro y llegando apenas, en los más felices de los casos, a cuatro euros, descartándose los casos de las traducciones gratuitas, hechas por el amor del arte, y el precio por las 
reediciones de las obras ya publicadas anteriormente. Los efectos de esta situación, generalizada a nivel nacional, se deducen fácilmente.

$\mathrm{Al}$ contemplar el panorama de las traducciones al rumano de la literatura latinoamericana observamos que en una proporción aplastante dominan los títulos relacionados con el fenómeno del Boom. Si los "cuatro centrales" del Boom tienen una gran visibilidad en la cultura rumana, también están bastante bien representados los autores cercanos a este centro - Roa Bastos, José Donoso, Juan Carlos Onetti, Octavio Paz, Juan Rulfo - así como a los escritores lanzados a la fama gracias al Boom, o sea los que, en las palabras jocosas de Donoso, integran el "proto-Boom" o el "Boom junior". Sin duda alguna, domina entre los autores argentinos, por el número de ediciones y reediciones, el nombre de Borges, cuyos principales cuentos se tradujeron bastante temprano, en 1972, pero en una traducción deficiente. En 1999 la editorial Univers volvió a publicar los cuentos completos de Borges, en dos tomos editados cuidadosamente, que no obstante retomaban algunas traducciones anteriores, algunas de ellas malogradas. A partir de 2006 la editorial Polirom lanzó la serie de autor Borges, donde, bajo la supervisión del gran traductor Andrei Ionescu, se publicó la entera obra borgeana, en nuevas traducciones, muy mejoradas, algunas de ellas inmejorables. Como en el caso de García Márquez, no solo se tradujeron las obras maestras: así, apareció Prosa completa en dos tomos (2006), Ensayos (2006), pero también los libros escritos en colaboración (Cărți scrise în doi, 2005, Cartea fiinţelor imaginare, 2006), una antología poética traducida con ritmo y rima por Andrei Ionescu (Poezii, 2005), Textos cautivos (2010), continuando la serie con los libros de conversaciones reunidos bajo el título Borges a los ochenta años, que se publicaron junto a Los libros y la noche (Borges la optzeci de ani. Cărţile şi noaptea, 2016) y, más recientemente, con la serie de conferencias de Borges sobre el tango (Tangoul 2018).

Otro autor del "proto-Boom" que suscitó el interés de los editores es Alejo Carpentier, cuya obra había sido traducida desde los años sesenta: a los seis títulos ya existentes, se añadieron Los pasos perdidos, además de republicarse tres de las novelas traducidas anteriormente (El ritual de la primavera, 2005; El arpa y la sombra, 2006; El recurso del método, 2006). Curiosamente, no se vuelve a publicar El siglo de las luces ni Concierto barroco, si bien la primera novela es un libro no solo clave de la literatura latinoamericana, sino además portador de las semillas de todo lo que ulteriormente se transformará en los estereotipos relacionados con el "realismo mágico", mientras Concierto barroco es un libro bellísimo que asimismo es breve, por lo cual igual habría podido suscitado el interés 
de los editores. Según se ve, es imposible operar con un determinismo mecánico para determinar las razones de elección de los títulos por parte de los editores.

Un éxito notable tiene también Adolfo Bioy Casares, del cual se volvieron a publicar todos los títulos ya existentes antes de 1989 y se publicaron en primera edición De un mundo a otro (Humanitas 2007), El sueño de los héroes (Curtea Veche 2009), Diario de la guerra del cerdo (Curtea Veche 2009), La tarde de un fauno (Curtea Veche 2009). También se destaca la reedición de Pedro Páramo, por RAO, en 2006 y la publicación en el mismo año de El llano en llamas de Rulfo, traducido por el mismo traductor de la novela rulfiana, el insigne hispanista Andrei Ionescu.

No se puede negar que varias editoriales rumanas se propusieron recuperar muchos, y en general los más importantes títulos traducidos en el régimen anterior: así, por ejemplo, se vuelve a publicar, en 2004, La vorágine de José Eustacio Rivera, cuya primera edición en rumano data de 1968; Don Segundo Sombra de Ricardo Güiraldes, publicada por primera vez en 1980; Cuentos de sangre y muerte, Univers, 2013, que retoma la edición de 1970. También se destacan las traducciones, en 2013, 2014 y 2017 de El juguete rabioso, Los siete locos y El criador de gorillas de Roberto Arlt. No se reeditan, en cambio, los libros de Arturo Uslar Pietri y de Miguel Ángel Asturias apenas se volvió a publicar en 2012 Los hombres de maíz por la editorial Univers, retraducida por Lavinia Similaru. En general, la regla es el aprovechamiento de la existencia de las traducciones que, por regla general, eran de altísima calidad, aunque en algunos casos las traducciones se rehacen, para bien, en algunos casos, o para mal. Asimismo, una obra como Yo el Supremo, de donde algunos (pocos) párrafos fueron censurados en 1982 se vuelve a publicar integralmente en 2007 por la Editorial Curtea Veche. A Ernesto Sábato, que desde el principio ha tenido una excelente acogida en Rumania, se le vuelven a publicar sus tres novelas más importantes y se le publican cinco ensayos más, a partir de 2014 abriéndose la serie de autor Sábato en la editorial Humanitas con las tres grandes novelas sabatianas todas vueltas a traducir por Tudora Şandru-Mehedinţi. Octavio Paz, por fin, tiene solo dos ensayos publicados: por un lado, Los hijos del limo, publicado en 2003 en una editorial de Cluj-Napoca, que no le dio mucha difusión, y vuelto a publicar por otra editorial de la misma ciudad en 2017 y, por otro lado, $L a$ doble llama, publicada por una editorial muy grande, Humanitas, en 1998, que consiguió darle una larga difusión y la reeditó en 2017.

En lo que respecta a los autores más jóvenes relacionados con el fenómeno del Boom, se remarca que Bryce Echenique, cuyo Un mundo para 
Julius también había sido conocido en la Rumania socialista, fue reeditado en 2006 y también, de su obra, fueron traducidos tres títulos más (El huerto de mi amada, 2004, Guía triste de París, 2006, La amigdalitis de Tarzán, 2010). Asimismo, un autor como Guillermo Cabrera Infante por fin aparece traducido al rumano con tres títulos: Tres tigres tristes, 2010, La ninfa inconstante, 2011, Cuerpos divinos, 2014. Desgraciadamente, un autor que actualmente es considerado un maestro incontestable para la nueva generación de narradores latinoamericanos, Manuel Puig, no tuvo la suerte de integrarse a su justo valor en la cultura rumana, ya que la única obra publicada antes de 1989, Boquitas pintadas, no volvió a publicarse ni se tradujeron otras novelas suyas.

Tampoco se puede negar que las editoriales rumanas también intentaron restañar ciertas ausencias lamentables: así, en 2011 se traduce El obsceno pájaro de la noche, precedida por otra obra menor de él (La misteriosa desaparición de la marquesita de Loria, 2008) y cuatro obras de Juan Carlos Onetti se traducen entre 2006 y 2008: El astillero, Vida breve, Los adioses, Historia del caballero de la rosa. Sin poner en duda los méritos de estas restituciones, estas apariciones tardías plantean una serie de problemas: por un lado, en la literatura de origen, se trata de clásicos que los rumanos leen al mismo tiempo que a los autores más recientes que, poco a poco, empiezan a irrumpir en la cultura rumana, creando pues varios problemas de perspectiva.

Un apartado especial lo merecen los autores que en los círculos de los defensores de la pureza estética, supuestamente no contaminada por el mercantilismo capitalista, están tildados de "comerciales". Efectivamente, los libros de Isabel Allende están integrados en una serie de autor que alcanza 21 títulos, reflejando fielmente la producción de la autora chilena (que tiene 23 títulos publicados hasta la fecha), lo que en absoluto nos parece un hecho negativo, más aun cuando los títulos que salieron paulatinamente desde 1998 fueron todos traducidos por una muy talentosa traductora rumana, Cornelia Rădulescu. Por su parte, Laura Esquivel no puede faltar en la cultura rumana actual, por sus dos títulos más conocidos, Como agua para el chocolate y Tan veloz como el deseo, los dos traducidos en 2004 por la misma excelente traductora Cornelia Rădulescu. Luis Sepúlveda y Tomás Eloy Martínez, autores también tildados de comerciales por los puristas, están representados con un número considerable de títulos: cinco libros del primero (Un viejo que leía novelas de amor, 2002; Nombre de toreador, 2004; Hot Line, 2004; Diario de un killer sentimental, 2004; Historia de una gaviota y del gato que la enseñó a volar, 2017) y dos del segundo (El vuelo de la reina, 2006; El cantor de tango, 2009). Ahora bien, muchos de los 
profesores que se enfrentan al crecimiento galopante de lo que se llama "analfabetismo funcional" se preguntan si no es preferible que la gente lea al menos estas novelas en vez de no leer nada. En cambio, el reverso de esta concepción es el fomento de la incapacidad de discernir entre la buena y la mala literatura que no afecta simplemente a los lectores sino que embrolla el espacio de reflexión crítica en su conjunto. Al respecto, Eloy Fernández Porta demostraba, a base de una comparación textual entre Javier Marías y Ray Loriga, que, a diferencia de lo que se podía esperar, no se da un grado mayor de pop culture en el segundo autor con respecto al primero, sino que los dos autores son pop y están en igual medida permeados por la lógica del consumo y de la comercialización. Según el autor de Afterpop, la incapacidad o la falta de voluntad de admitir esta realidad lleva a unos fenómenos tan aberrantes como el "trastorno de la percepción que lleva a creer que algunos objetos de consumo mayoritarios - las novelas serias que se venden a miles - son minoritarios" (Fernández Porta 2010: 26). El caso de ciertos libros de Vargas Llosa es emblemático al respecto y entonces uno se pregunta si no es más aceptable la actitud de un autor que no tiene la pretensión de integrarse en la "alta cultura", sino que acepta simplemente que sus libros gusten y se vendan, como es, digamos, el caso de Isabel Allende.

Ahora bien, la literatura actual de Latinoamérica se caracteriza por una inmensa variedad que si bien dificulta el diseño de un panorama aceptable y dé la impresión de "desbandada" (Guerrero 2009), no solo tiene un potencial exportable inmenso desde el punto de vista literario sino que también tiene grandes autores, lo que no viene a significar siempre lo mismo, aunque a veces sí. Por ejemplo, es significativo que el propio Roberto Bolaño tuvo una excelente acogida en el espacio rumano: desde 2009 hasta el presente el número de títulos bolañianos publicados en Rumania llegó a trece, incluyéndose, lo que es bastante raro, dos tomos de poesía y las novelas de grandes dimensiones Los detectives salvajes y 2666 (esta última publicada en tres tomos, cuando la tendencia general va hacia a publicación de unas obras lo más cortas posibles). A su muy buena acogida, probada por el número de reseñas y comentarios en los foros literarios de internet, se debió la excelente traducción: las dos grandes novelas de Bolaño, por ejemplo, fueron traducidas por Dan Munteanu Colán, traductor de larga reputación, cuya carrera empezó en los años sesenta y que sigue siendo, al igual que Andrei Ionescu, Mihai Cantuniari y pocos más, uno de los más destacados y talentosos traductores rumanos de la actualidad, él destacándose también por su apabullante productividad. Se debe no obstante reconocer que el estatuto de Bolaño 
es especial dentro del propio canon latinoamericano y que, por más que abomine el autor los mecanismos de creación de la fama, su nombre llegó a convertirse, para bien o para mal, en una marca comercial.

Intentemos, no obstante, rastrear los nombres de menor resonancia en el extranjero, que si bien en algunos casos son autores de culto o incluso ya autores clásicos en su espacio de origen, llegaron a Rumania por un circuito que tiene más que ver con las consideraciones estrictamente estéticas que con las razones ligadas a la fama comercial. La selección por países nos resulta más cómoda, si bien, como vimos en el caso de algunos de ellos la nacionalidad dejó de representar un elemento identitario potente. De la literatura argentina, podemos destacar que de los maestros de la generación de los setenta, Juan José Saer está representado con un único título (El entenado, 2006), Ricardo Piglia también con uno, bastante reciente (El camino de Ida, 2016) y César Aira, con dos títulos (Varamo, 2007, Un episodio en la vida del pintor viajero, 2011). De esta misma generación, pero de perfil menos acusado, se publican dos libros de Abel Posse (Los perros del paraíso, en dos traducciones distintas y en editoriales diferentes, en 1995 y en 2005; y Daimon, 2008) De los autores más jóvenes, que entran en la categoría del best-sellers, si bien su calidad literaria es variada, se pueden nombrar Guillermo Martínez con tres títulos traducidos entre 2006 y 2008 (Crímenes imperceptible, La muerte lenta de Mariana B., Acerca de Roderer), Federico Andahazi con cuatro títulos traducidos entre 2007 y 2011, Cristina Bajo con un título (El jardín de los venenos, 2009), Patricio Sturlese con un título (El inquisidor, 2010), Marcelo Figueras (Kamchatka, 2013), Pablo de Santis con un título (El calígrafo de Voltaire, 2008) y Lucía Puenzo (El niño pez, 2011). A Mariana Enríquez, la nueva estrella de lo neogótico argentino, se le tradujo - de forma excepcional, por el mejor traductor de la actualidad de Rumania, Marin Malaicu-Hondrari - el libro de cuentos Las cosas que perdimos en el fuego (Editorial Art, 2017), libro que de hecho había lanzado a la escritora al circuito de la fama mundial. Se añaden autores de menor relieve, de varias generaciones, como Carlos Balmaceda, con un título (El manual del caníbal, 2008), que tuvo una acogida sorprendentemente positiva en Rumania, o Alicia Dujovne Ortiz con dos títulos (La pasión del conde Toulouse-Lautrec, 2001 y Dora Maar, 2012).

De la literatura mexicana se destaca la traducción de dos libros de Mario Bellatín (incluidos en una sola edición, Salón de belleza y Lecciones para una liebre muerta, 2008), de una novela de Antonio Ortuño (El buscador de cabezas, 2009) y de dos libros de Guillermo Arriaga (Un dulce olor a muerte y Escuadrón guillotina, 2008). También se encuentran, afortunadamente, dos títulos de Sergio Pitol: Domar a la divina garza, 
2007; El desfile del amor, Art, 2010. Una novela bastante simple, pero de mucho éxito internacional, como Fiesta en la madriguera de Juan Pablo Villalobos se publica con tanto éxito en 2012 que un año más tarde se hace una reedición; recientemente, otro libro de él se publicó en Rumania: Te vendo un perro (Editorial Paralela 45, 2019, traducido por el mismo excelente e incansable Marin Malaicu-Hondrari). De forma poco sorprendente, también una autora tildada de comercial por los puristas del canon, Ángeles Mastretta figura en la oferta editorial, pero con un solo título, el más célebre, Arráncame la vida, traducido en 2002.

La literatura chilena en Rumania está dominada por los nombres de Isabel Allende, Roberto Bolaño y, en menor medida, de Luis Sepúlveda. De Antonio Skármeta se traducen dos libros (El cartero de Neruda, 2004, Neruda visto por Skármeta, 2007, El baile de la victoria, 2012), de Jorge Edwards (La casa de Dostoyevski, 2009 y El origen del mundo, 2012) y de Carlos Franz dos títulos (El desierto, 2011 y El lugar donde estuvo el Paraíso, 2012).

De la literatura peruana más actual se traduce un título de Alonso Cueto (La hora azul, 2010), Jaime Bayly, con dos títulos ( $Y$ de repente, un ángel, 2007, La canalla sentimental, 2010) y el autor de superventas como Sergio Bambaren con dos títulos (El delfín y La estrella, 2006).

La literatura de la Colombia actual está mucho mejor representada en comparación con otras literatura del continente: se importan, como autores más nuevos, a Hector Abad Faciolince (El olvido que seremos, 2014), Juan Gabriel Vázquez (El ruido de las cosas al caer, 2015), Ángela Becerra (Ella que todo lo tuvo, 2010), Evelio Rosero (Los ejércitos, 2009), Laura Restrepo con dos títulos (Delirio, 2006, Dulce compañía, 2008), Santiago Gamboa con dos títulos (Los impostores, 2010 y Perder es cuestión de método, 2011), pero en este último caso, desgraciadamente, la traducción está plagada de errores y el descuido de la edición es evidente. En 2017 se publican dos novelas de Alejandro Zambra: Bonsai y La vida privada de los árboles. Se destaca también la recuperación de un maestro de la generación anterior, como Álvaro Mutis con un único título, Maqroll el gaviero, 2004. El nombre de un maestro como Fernando Vallejo penetró recientemente en la cultura rumana, por la publicación de La virgen de los sicarios y El desbarancadero en 2016.

No se traducen títulos nuevos de la literatura boliviana, ecuatoriana ${ }^{4}$ y venezolana actual. De la literatura paraguaya se publica

\footnotetext{
${ }^{4}$ Hay no obstante un libro de cuentos de un autor muy poco conocido en su país, Renato Guiño, que estudió parte de su carrera universitaria en Rumania; su libro aparece en Rumania con el título Delirul iubirii (Delirul iubirii), Self Publishing, 2014. Parece que más bien se trata de una autoedición.
} 
en 2015 una novela, El invierno de Gunter de Juan Manuel Marcos, por la Editorial Diacritic de Timisoara. La literatura uruguaya actual tampoco está bien representada, traduciéndose solo un título de Carmen Posadas, Pequeñas infamias, 2004, por una editorial bastante pequeña, Fabulator de Bucarest, por lo cual el libro tuvo una difusión limitada.

La literatura centroamericana carece de muchos títulos traducidos al rumano: Movimiento perpetuo de Augusto Monterroso salió en 2009 en una editorial de Timisoara, Bastion, que no consiguió resistir mucho tiempo, por lo cual el libro no se difundió suficientemente. En 2019 apareció la novela Lo demás es silencio en la gran editorial Polirom, en la traducción de Marin Malaicu-Hondrari. Rodrigo Rey Rosa está presente solo con un libro, Otro zoo, publicado en rumano en 2006, traducido por otra excelente traductora, Cornelia Radulescu. Un libro esencial para entender el entero mundo caribeño, La biografía del Caribe de Germán Arciniegas, se tradujo durante el período socialista (1978), pero ningún editor del período actual tuvo la iniciativa de republicarlo. En cambio, por razones ligadas al interés que suscita el tema cubano, la literatura de la Isla tiene una mucha mayor representación y afortunadamente los autores traducidos se publicaron por unas editoriales importantes de Rumania, que le proporcionaron una buena difusión: de Jesús Díaz se traducen dos novelas (Dime algo sobre Cuba, 2007, Las cuatro fugas de Manuel, 2008), de Juan Pedro Gutiérrez, Trilogía sucia de la Habana, 2007, de Daína Chaviano, La isla de los amores infinitos, 2010, de Mayra Montero, Púrpura profundo, 2007.

Concluyendo, no se puede negar que, a pesar de la dominación del paisaje cultural por los autores asociados con el Boom que todavía se publican en Rumania, el relativo gran número de autores latinoamericanos nuevos traducidos al rumano aboga a favor de un cambio con respecto a la recepción de la literatura del subcontinente latinoamericano en este espacio cultural. El problema queda ligado a su aparición en un contexto en que la competencia hecha por Youtube y Netflix a la cultura escrita, las tiradas reducidas, la disminución del número de librerías etc. tiene como consecuencia una bajada del número de personas capaces de una lectura sosegada y reflexiva. La oferta cultural hecha por los editores rumanos en lo que concierne a la literatura latinoamericana no es despreciable, pero lo que es seguro es que ella llega a un público que pierde paulatinamente la confianza en el valor de un tipo de cultura basado en la acumulación paciente y el disfrute gratuito del arte, hecho que es natural en una época regida por los valores de la autoafirmación, el pragmatismo y el éxito a cualquier precio. Decía Borges: en comparación con la escritura, "leer es 
un acto más resignado, más civil, más intelectual" (Borges 1974: 289). Es difícil creer que, con la excepción de los hispanistas interesados en la literatura latinoamericana por razones profesionales, un lector común cultivado pueda percibir en su apabullante variedad la propuesta de los actuales escritores del espacio latinoamericano y no recurra a los "atajos" dados por los estereotipos culturales ya existentes (exotismo, realismo mágico, etc.), pero si bien las percepciones cambian más difícilmente que la dinámica de los hechos concretos, las transformaciones de los gustos y de las modas se da, no obstante, a lo largo del tiempo. A los hispanistas nos sigue incumbiendo la tarea de llamar la atención sobre las transformaciones del discurso literario latinoamericano en nuestras propias culturas, a través de las traducciones, reseñas y estudios críticos publicados en nuestras lenguas nativas, y asimismo nos compete conocer la actividad traductiva de los espacios culturales colindantes, a fin de poder observar las similitudes y diferencias con respecto a la recepción de un mismo fenómeno cultural, el que se está gestando en el ámbito hispánico. Esperamos que esta descripción comentada del acervo literario latinoamericano puesto al alcance de los rumanos en los últimos treinta años pueda inspirar a los traductores, editores y agentes culturales del entero espacio de Europa Central y del Sureste no solo para proponer a los lectores de cada país de esta zona una literatura hispánica de alta calidad estética, sino para concienciar los vínculos inextricables entre la calidad estética, la moda, los hábitos de lectura y las variaciones del concepto de cultura en una época de cambios acelerados.

\section{BIBLIOGRAFÍA}

ABC cultural, 21/05/2018: https://www.abc.es/cultura/ libros/abci-espana-aumenta-produccion-libros-46-porciento-2017-201805211433_noticia.html Web. 12 Dic. 2018.

Becerra Mayor, David et al. Que hacemos con la literatura. Madrid: Akal, 2013. Impreso.

Bértolo, Constantino. La cena de los notables, Cáceres: Periférica, 2008. Impreso.

Borges, Jorge Luis. Obras completas. Buenos Aires: Emecé, 1974. Impreso.

Ceobanu, Ioana et al. Studiu privind piața de carte în România. Institutul național pentru cercetare și formare culturală culturdata.ro, 2016. Imprimate.

Cortés, Carlos. "La literatura latinoamerican (ya) no existe". Cuadernos latinoamericanos, 592 (1999): 59-67. Impreso. 
Fernández Porta, Eloy. Afterpop. La literatura de la implosión mediática. Barcelona: Anagrama, 2010. Impreso.

Fornet, Jorge. "Y finalmente, ¿existe una literatura latinoamericana?". La Jiribilla, La Habana, 9-15 de junio de 2007, 1-15.

https://lh2.weebly.com/uploads/2/3/9/0/23909114/fornet_ jorge_y_finalmente_existe_una_literatura_latinoamericana.pdf Web. 12 Ene. 2019.

Fresán, Rodrigo. "Apuntes (y algunas notas de pie) para una teoría del estigma: páginas sueltas del posible diario de un casi ex joven escritor sudamericano". Palabra de América, Barcelona: Seix Barral, 2004. Impreso.

Guerrero, Gustavo. "Nueva narrativa del extremo Occidente: la encrucijada de la recepción internacional". Letras libres, enero (2009): 22-28. Impreso.

Guerrero, Gustavo. "La desbandada. 0 por qué ya no existe la literatura latinoamericana". Letras libres, junio (2009): 27-28. Impreso.

Ilian, Ilinca. "Aproximación al tema de la recepción del boom latinoamericano en la Rumanía de la época socialista". Anđelka Pejović et al. (Eds.). Estudios hispánicos en la cultura y ciencia serbia - Actas de la Primera conferencia nacional de hispanistas serbios (Facultad de Filología y Artes de Kragujevac, 28-29 noviembre de 2014). Kragujevac: Editorial de la Facultad de Filología y Artes Universidad de Kragujevac. 2016: 27-40. Impreso.

Ilian, Ilinca. "Contexto y recepción de la literatura latinoamericana del siglo XX en la Rumania socialista". Cuadernos del CILHA, 28 (2018): 45-62. (2018a) http://qellqasqa.com.ar/ojs/index.php/cilha/ article/view/305 Web. 22 Mar. 2019.

Ilian, Ilinca. "Las traducciones de la literatura latinoamericana en la Rumania de hoy". Colindancias, 9 (2018): 57-90. (2018b) Impreso.

Noël, Bertand. L'Outraga aux mots. Paris: P.O.L., 2011 [1975]. Impreso.

Rad, Ilie. Incursiuni în istoria presei românești. Cluj-Napoca: Accent, 2008. Imprimate.

Robbins, Timothy \& José Eduardo González (Eds.). New Trends in Contemporary Latin American Narrative. Post-National Literature and the Canon. London: Palgrave Macmillan, 2014. Print.

Simionescu, Dan \& Gheorghe Buluță. Pagini din istoria cărţii românești. București: Ion Creangă, 1981. Imprimate.

Surcel, Vasile. "Lipsa plăcerii de a citi, deja o tradiție la români”, Cotidianul, 27.08.2017. https://www.cotidianul.ro/lipsa-placerii-de-a-citideja-o-traditie-la-romani/ Web. 12 Dic. 2018. 
Vargas Llosa, Mario. La civilización del espectáculo. Madrid: Alfaguara, 2012. Impreso.

Volpi, Jorge. "El fin de la narrativa latinoamericana". Palabra de América. Barcelona: Seix Barral, 2004. Impreso.

VV.AA. Sinteza: "Carte pentru minte, inimă şi naţiune", resultados del sondeo IRES "Obiceiurile de lectură ale românilor" (Los hábitos de lectura de los rumanos) realizado en octubre 2015 sobre un muestreo de 1002 personas mayores de 18 años a través del método CATI). Sinteza 34 (2016): 11-25. Imprimate.

VV.AA. Panorámica 2016: Panorámica de la edición española de libros 2016: Análisis sectorial del libro, Madrid: Ministerio de Educación, Cultura y Deporte, 2017. Impreso.

VV.AA. The Book Sector in Europe: Facts and Figures, Federation of European Publishers. 2017. Print.

Wischenbart, Rüdinger. The Business of Book - Publishing in the Age of Attention Economy. Frankfurt: Frankfurter Buchmesse Business Club, 2019. Print.

\section{THE LATIN AMERICAN LITERATURE: WHAT AND HOW IS TRANSLATED IN ROMANIA TODAY}

\section{Summary}

The article contains a commented description of Romanian translations from Latin American literature. The material is intended to be related to the presence of the same literature in the cultural spaces of other countries in Central and Southeast Europe. It is the result of an already long investigation of the translation phenomenon from Spanish into Romanian and it highlights certain traits characteristic of the Romanian publishing scene in relation to Latin American culture: a large number of authors related to the phenomenon of the Boom and the difficulty of introducing new Latin American authors in Romania in the context of a decline in reading practice reflected in statistics. We will discuss also a series of questions about the reading practice in the current advanced postmodern context.

Keywords: reception of Latin American literature, Romania, Central and South-East Europe, editorial policy, lecture. 